\title{
O ENSINO DE ENFERMAGEM PSIQUIÁTRICA E A LEI DO EXERCÍCIO PROFISSIONAL DA ENFERMAGEM
}

Sônia Barros*

Marli Alves Rolim**

BARROS, S.; ROLIM, M.A. O ensino de enfermagem psiquiátrica e a lei do exercício profissional da enfermagem. Rev. latino-am.enfermagem, Ribeirão Preto, v.4, n.1, p.47-54, janeiro 1996.

O presente trabalho trata dos questionamentos surgidos durante discussões sobre a lei do exercício profissional da Enfermagem e como ela tem sido contemplada no desenvolvimento do ensino teórico-prático da disciplina Enfermagem Psiquiátrica I, da Escola de Enfermagem da Universidade São Paulo.

UNITERMOS: ensino, lei do exercício profissional de enfermagem, enfermagem psiquiátrica

No decorrer do "I e II Fóruns de estudos sobre o ensino da disciplina Enfermagem Psiquiátrica I", da Escola de Enfermagem da Universidade de São Paulo, foram abordados temas como "Padrões mínimos de assistência de Enfermagem Psiquiátrica", "Currículo mínimo de enfermagem", "Lei do exercício profissional", bem como Avaliação docente e discente do ensino da referida disciplina. Vale lembrar que estes Fóruns tinham como pano de fundo o processo de Reorientação Curricular da Escola de Enfermagem da Universidade de São Paulo.

\footnotetext{
*Enfermeira. Assistente do Departamento de Enfermagem Materno-Infantil e Psiquiátrica da Escola de Enfermagem da Universidade de São Paulo - Disciplina Enfermagem Psiquiátrica.

**Enfermeira. Professor Doutor do Departamento de Enfermagem Materno-Infantil e Psiquiátrica da Escola de Enfermagem da Universidade de São Paulo - Disciplina Enfermagem Psiquiátrica
} 
Questionamentos importantes surgidos sobre a "Lei do exercício profissional" e a sua regulamentação e como ela tem sido contemplada no desenvolvimento do ensino teórico-prático de Enfermagem Psiquiátrica I, motivaram o presente estudo.

Os pontos levantados e que embasaram a nossa discussão foram os seguintes:

01. O relacionamento terapêutico, da forma como é ensinado e desenvolvido na prática, se caracteriza como consulta de enfermagem?

02. Ensinamos o aluno a fazer prescrição de enfermagem?

03. Na área de Enfermagem Psiquiátrica, o que é considerado paciente grave, com risco de vida?

04. O que consideramos cuidados de enfermagem de maior complexidade técnica e que exigem conhecimentos de base científica?

05. Os conteúdos teóricos abordados, bem como o ensino desenvolvido na prática capacita o aluno a tomar decisões imediatas?

06. No decorrer do processo ensino-aprendizagem da disciplina são desenvolvidos conteúdos específicos que complementam outros, adquiridos até então na graduação, que capacitaram o aluno a elaborar, executar e avaliar programas de saúde e planos assistenciais de saúde?

07. Os conhecimentos desenvolvidos favorecem um interrelacionamento com os outros membros da equipe

08. Existe contribuição da disciplina, no sentido de abordar conteúdos específicos que facilitem a participação do aluno/enfermeiro em projetos de construção ou reformas da unidade de internação?

09. Estamos alerta e, ao mesmo tempo, alertando os alunos sobre os possíveis danos causados pelo desenvolvimento de relacionamento não terapêutico com o paciente e sobre a prevenção e detecção destes?

10. Ministramos conteúdos específicos de saúde mental que permitam ao aluno fazer educação em saúde? Qual é a nossa concepção de "Saúde Mental" e de "Educação em Saúde"?

Isto posto, gostaríamos de salientar que foi considerado pelo grupo participantes do Fórum, que a disciplina Enfermagem Psiquiátrica tem por objetivo contribuir para a formação do enfermeiro "generalista" e, portanto, o seu conteúdo programático não é suficiente par a formação de especialista da área, bem como não é essa a pretensão.

Além disso, consideramos também que o curso de graduação em enfermagem não dá conta de um produto acabado, o enfermeiro, capacitado par atender plenamente a lei do exercício profissional. Esta, por sua vez, apesar de aprovada, apresenta pontos polêmicos e necessita que os seus diversos aspectos sejam amplamente debatidos em todo o Brasil.

A partir das considerações acima, chegamos a algumas conclusões, quais sejam: 
01. O relacionamento terapêutico não é considerado uma consulta de enfermagem, mas sim prescrição de enfermagem que deveria ser decorrente daquela. Concluímos que seria extremamente útil utilizar a consulta de enfermagem, da forma como já vem sendo ensinada em outras disciplinas do curso de graduação, como passo inicial para a prescrição do relacionamento terapêutico.

02. Ensinamos o aluno a fazer a prescrição de enfermagem, pois, quando planeja a assistência de enfermagem psiquiátrica, prescreve cuidados específicos a cada tipo de comportamento, sintoma ou outros problemas do paciente.

03. Na área de enfermagem psiquiátrica, consideramos paciente grave todo aquele com distúrbio mental, uma vez que os sintomas psiquiátricos determinam imprevisibilidade de seu comportamento o que, por sua vez, pode colocar sua vida em risco, assim como provoca sérios prejuízos à qualidade de vida do indivíduo. É conclusão do grupo que a disciplina, na sua especificidade, contempla esse ponto da legislação, pois ministra conteúdos teórico/práticos suficientes para isso.

04. Consideramos cuidados de enfermagem de maior complexidade técnica os processos de "Intervenção em Crise" e de "Relacionamento Terapêutico". Entretanto, a validade do ensino do Relacionamento Terapêutico, enquanto processo, no curso de graduação, foi amplamente discutida e, a maioria do grupo concorda que o Relacionamento Terapêutico é conteúdo que deve ser desenvolvido em cursos de especialização. Na graduação, achamos que o aluno deve receber conteúdos que o habilitem a manter relacionamento profissional, ou interpessoal, com finalidade terapêutica, mas não com caráter de processo que o relacionamento terapêutico tem enquanto método ou técnica psicoterápica.

05. O grupo acredita que durante o ensino de "Emergências Psiquiátricas" o aluno pode desenvolver mais a capacidade de tomar decisões imediatas e, portanto, é assunto que deve ser hipertrofiado na prática.

06. São abordados e discutidos em sala de aula, temas como "Políticas de Saúde Mental", "Programas de Saúde Mental em unidades básicas de saúde (UBS) e em Ambulatórios de Saúde Mental", que do nosso ponto de vista ajudariam o aluno a elaborar, executar e avaliar programas e planos assistenciais de saúde. Sentimos, contudo, falta de vinculação destes temas á prática de campo do aluno.

07. Percebemos que já na teoria não é enfatizado o trabalho em equipe e, na prática, o aluno desenvolve atividades isoladas; às vezes faz contato com algum profissional apenas para obter informações complementares. São poucas as iniciativas de desenvolvimento de trabalho conjunto.

08. Acreditamos que conteúdos básicos que facilitem a participação do aluno/enfermeiro em projetos de construção ou reformas de unidade de internação são, provavelmente, adquiridos na disciplina de Administração em Enfermagem. Todavia, em Enfermagem Psiquiátrica, o conhecimento sobre "Ambiente terapêutico" complementa essas informações. Achamos que conhecimentos mais complexos e mais específicos para tal habilidade devem ser adquiridos em cursos de especialização. 
09. O grupo de docentes da disciplina concluiu que o processo de relacionamento terapêutico pode causar danos ao aluno e ao paciente. No entanto, não aprofundamos a discussão para especificar quais seriam esses danos

10. O conteúdo oferecido aos alunos sobre "Saúde Mental" é considerado pouco e também não é desenvolvido na prática. Por outro lado, quando se faz educação é para o indivíduo já doente e, às vezes, para sua família, mas com enfoque de controle do comportamento doentio.

Com relação às concepções de "Educação em saúde" e de "Saúde Mental", o grupo não chegou a um consenso.

Frente a essas conclusões encaradas como levantamento de problemas referentes à lei do exercício profissional, nós, autoras do presente trabalho, faremos algumas sugestões indicativas de parte do conteúdo programático da disciplina Enfermagem Psiquiátrica, numa tentativa de maior aproximação da legislação vigente, contemplando as reflexões do grupo.

Para atingir a prescrição de enfermagem, o passo inicial deve ser por meio da consulta de enfermagem, seguindo modelo adotado pelas autoras disciplinas de graduação, como "Fundamentos em Enfermagem" e "Enfermagem Preventiva e Comunitária".

Apesar de o conteúdo programático de Enfermagem Psiquiátrica I contemplar distúrbios psicopatológicos e os cuidados de enfermagem referentes a eles, ressaltamos que a abordagem feita é um tanto quanto unilateral, uma vez que deixa de contemplar outros fatores que intervêm no risco de vida, dentro do processo saúde-doença, tais como: condições de vida, acesso à assistência à saúde, qualidade da assistência prestada. Esclarecemos que a idéia é deixar de ter a doença como objeto da assistência e passar a enfatizar a "existência-sofrimento" dos pacientes e sua relação com o corpo social (ROTELLI, 1990).

Consideramos o processo de "Intervenção em Crise" conteúdo básico necessário para habilitar o aluno a tomar decisões imediatas, não só em situações de emergência psiquiátrica, como em outras que possivelmente o aluno enfrentará no seu cotidiano.

Há vários anos, cientistas sociais profissionais da área da saúde mental têm estudado os efeitos das crises nos indivíduos, famílias e comunidades. A teoria da crise tem suas raízes históricas no trabalho de Eric Lindemann, que se tornou famoso pelo seu estudo das reações emocionais dos sobreviventes do incêndio no Cocoanut Grove, um clube noturno de Boston, em 1942. Seus achados sobre os sintomas e manejo da tristeza aguda continuam sendo o trabalho clássico na área Gerald Caplan e seus colegas continuaram o trabalho e a pesquisa de Lindemann, apesar da intervenção na crise ser reconhecida como modalidade de tratamento apenas nos anos 60. Durante este período Gerald Caplan fez numerosas contribuições para a literatura sobre o assunto e foi peça fundamental no desenvolvimento de uma teoria para explicar as manifestações de uma crise em pessoas essencialmente 
saudáveis, bem como para a postulação de técnicas de intervenção (TAYLOR, 1992).

Desde então, numerosos profissionais das disciplinas da saúde contribuíram par a estruturação de um corpo de conhecimentos sobre o assunto, entre eles as enfermeiras Aguilera e Messick que avançaram no campo da teoria da crise, não só em termos de conhecimento, como no processo de intervenção (BURGUESS, 1985). Portanto, achamos que esse tópico deva ser mais detalhado na teoria e melhor sedimentado na prática, como possibilidades de o aluno experimentar tal tipo de intervenção.

Sabemos que o modelo descrito por Caplan, como afirmam CUSTÓDIO; JORGE (1994), foi formulado para pessoas normais, ou seja, que não eram mentalmente doentes. A crise não era encarada como patológica, mas a intervenção em crise mostrava-se útil na prevenção da doença mental.

Portanto, possibilitar ao aluno mais experiências em Emergências Psiquiátricas seria uma oportunidade para que ele adquirisse a teoria e a prática do processo de intervenção em crise, uma vez que a esses locais comparecem não só doentes mentais, como pessoas em processo de crise pelas mais variadas situações de perdas, sejam elas de pessoas significativas (por morte ou separação), de status social (por demissão ou rebaixamento do cargo, por doença, entre outros) e de capacidade intelectual ou física devido à acidente ou doença grave.

Além disso, a integração com outras disciplinas, para que, ao longo do curso de graduação o aluno pudesse já ir identificando situações de crise, ou mesmo de doença mental, facilitaria o desenvolvimento de tal habilidade.

Partindo do pressuposto de que Relacionamento Terapêutico, como processo psicoterapêutico, é conteúdo de maior complexidade, deve, portanto, ser abordado em curso de Especialização. Achamos que caberia para a graduação desenvolver conceitos que habilitariam o aluno a desenvolver relacionamento interpessoal/profissional, como os que se seguem:

- Componentes básicos do relacionamento interpessoal, segundo HOFLING (1970).

- Medidas terapêuticas em enfermagem

1. Aferecimento de apoio

2. Colocação de limites

3. Ajuda na expressão de pensamentos e sentimentos

\subsection{Comunicação terapêutica}

Entretanto, quaisquer que sejam as opções adotadas, relacionamento terapêutico na especialização ou relacionamento interpessoal na graduação, achamos que tal prática pode acarretar danos tanto para o paciente como para o aluno. Uma das formas de se diminuir os riscos é a supervisão direta do docente, que orienta individualmente os alunos, como vem sendo feita.

Os temas "Políticas de Saúde Mental" e "Programas de Saúde Mental em unidade Básica (UBS) e em Ambulatórios de Saúde Mental”, abordados teoricamente em sala de aula, devem ser conhecidos como acontecem nos 
ambulatórios e nas UBS. Sugerimos, portanto, que os alunos façam pelo menos visitas, com entrevistas aos membros das equipes, para conhecer como se desenvolvem os trabalhos preconizados naqueles programas e políticas de Saúde Mental.

Além disso, acreditamos que facilitaria a aprendizagem do aluno, se as docentes tivessem a postura de estar relacionando as políticas de saúde mental com o trabalho desenvolvido nas diversas instituições, ou seja, apontar para os movimentos de transformação nos hospitais psiquiátricos, a falta de inserção dos enfermeiros nos programas de saúde mental das UBSs, dificuldades encontradas na assistência ao cliente, problemas com recursos humanos, entre outros.

Com relação à equipe de saúde, achamos interessante que ao menos o aluno pudesse conhecer a prática desses profissionais, por meio de seus próprios relatos. Achamos que o assunto merece mais discussões.

Antes de definirmos conteúdos sobre Saúde Mental necessários para se fazer "Educação em Saúde", é fundamental que o grupo chegue à conclusão do que entende por "Educação em Saúde" e "Educação em saúde mental" e, a partir daí, delimitar o conhecimento necessário para tal.

Percebemos que o grupo não partilha, de forma unânime, de um único conceito de Saúde Mental. Entretanto, um dos mais conhecidos e aceitos é o contido em uma das bibliografias adotadas pela disciplina, qual seja, HOLFLING (1970).

“... Saúde Mental é o funcionamento completo e harmonioso de toda a personalidade. A avaliação de saúde mental pode ser feita pela capacidade do indivíduo de adaptar-se ao meio ou de contribuir construtivamente para provocar mudanças...".

Algumas críticas já são feitas a este conceito, no que diz respeito à noção de conformismo e adaptação a um conjunto de normas sociais, geralmente pressupostas arbitrariamente, bem como a não consideração das condições de vida da pessoa.

Além disso, introduz uma concepção de saúde mental, como um estado independente do processo saúde doença.

Entendendo saúde mental como elemento básico do processo saúde doença e a saúde e a doença como dois pólos de um fenômeno essencialmente coletivo, ainda que compreenda manifestações individuais concretas, sugerimos o conceito de STOLKINER (1985) para discussão. Esta autora acredita que o conceito de saúde mental está embutido no conceito geral de saúde que é

“... o máximo bem-estar possível em cada momento histórico e circunstância determinada, produto da interação permanente de transformação recíproca entre o sujeito (sujeito social) e sua realidade".

Acreditando que ao fazer "Educação em Saúde", mais especificamente com relação à Saúde Mental, a enfermeira carrega consigo concepções de Homem que irão refletir nesse processo educativo. Consideramos, então, de suma importância que a discussão sobre a concepção de Homem anteceda essas reflexões sobre o processo saúde-doença mental. 
Trazemos como sugestão, as considerações de VIOLANTE (1988) sobre o assunto. Para ela, Homem "é um ser não determinado sócio-historicamente, mas por meio de um conjunto de mediações que se efetivam no âmbito do mundo próximo do sujeito, bem como, em seu fórum íntimo sócio-individual. Neste âmbito se entrelaçam sua constituição biológica, suas experiências reais e fantasiadas da vida e seu modo subjetivo de apropriá-las e de atribuir-Ihes sentido, de acordo com sua capacidade cognitiva, seus desejos conscientes e inconscientes, seus conflitos, suas defesas e ansiedades".

\section{PSYCHIATRIC NURSING TEACHING PROCESS AND THE LEGISLATION AFFECTING NURSING PRACTICE}

This paper presents some questions about the legislation that affects nursing practice. Authors analyzed how the principles of this legislation have been used in the psychiatric, nursing teaching process.

UNITERMS: teaching, psychiatric nursing, legislation

\section{ENSEÑANZA DE ENFERMERÍA PSIQUIÁTRICA Y LA DEL EJERCICIO PROFESIONAL}

Este estudio trata de algunos asuntos acerca de la legislación de la práctica de la Enfermería Psiquiátrica. Fue analizado cómo los principios de la legislación han sido abordados en el proceso de la enseñanza de Enfermería Psiquiátrica.

UNITERMOS: enseñanza, enfermería, psiquiátrica, legislación

\section{REFERÊNCIAS BIBLIOGRÁFICAS}

01. ASSOCIAÇÃO BRASILEIRA DE ENFERMAGEM. A "nova" lei do exercício profissional da enfermagem: uma análise crítica. Brasília, 1987. 
02. BURGUESS, A W. Psychiatric nursing. New Jersey, 1985. cap. 36, p. 804-32: Crisis Theory and Intervention.

03. CUSTÓDIO, O.; JORGE, M.R. Crise e intervenção em crise: considerações básicas. Boletim de Psiquiatria, v. 27, n. 2, p. 7-12,1994.

04. HOFLING, C.K. et al. Enfermería psiquiátrica. México: Interamericana, 1970. cap. 3, p. 23-55: Comprensión de las relaciones entre enfermera y paciente.

05. ROTELLI, F. et al. Desinstitucionalização. São Paulo: Hucitec, 1990. cap. 1, p. 17-59: Desinstitucionalização, uma outra via: a reforma psiquiátrica italizana no contexto da Europa ocidental e dos "Países Avançados".

06. STOLKINER, A Practicas en salud mental. Inv.Educ. Enf., v. 6, n.1, p. 31-61,1988.

07. TAYLOR, C.M. Fundamentos de enfermagem psiquiátrica de Mereness. 13. ed. Porto Alegre, Artes Médicas, 1992. cap. 24, p. 370-81: Crise-teoria e intervenção.

08. VIOLANTE, M.L.V. Da construção bio-sócio-psicológica do sujeito. Psicologia Soc., v. 3, n-4, p. 12, 1988. 